\title{
Evaluation of comprehensive myocardial contractility in children with Kawasaki disease by cardiac magnetic resonance in a large single center
}

\author{
Qiong Yao ${ }^{1}$, Xi-Hong $\mathrm{Hu}^{1 \#}, \mathrm{Li}-\mathrm{Li} \mathrm{He}^{2 \#}$ \\ ${ }^{1}$ Department of Radiology, Children's Hospital of Fudan University, Shanghai, China; ${ }^{2}$ Department of Ultrasound, Children's Hospital of Fudan \\ University, Shanghai, China
}

Contributions: (I) Conception and design: Q Yao; (II) Administrative support: XH Hu; (III) Provision of study materials or patients: Q Yao, LL He; (IV) Collection and assembly of data: LL He; (V) Data analysis and interpretation: Q Yao, XH Hu; (VI) Manuscript writing: All authors; (VII) Final approval of manuscript: All authors.

"These authors contributed equally to this work.

Correspondence to: Xi-Hong Hu. Department of Radiology, Children's Hospital of Fudan University, Shanghai 201102, China.

Email: m18964783309@163.com.

Background: Children with Kawasaki disease (KD) and coronary artery lesions (CALs) can develop myocardial ischemia, fibrosis, and abnormal contractility. We aimed to assess the association between myocardial mechanical deformation with myocardial fibrosis, ischemia, and CALs.

Methods: In total, $76 \mathrm{KD}$ and 20 healthy volunteers received cardiac magnetic resonance (CMR). Peak systolic left ventricular (LV) longitudinal, radial, and circumferential strain and strain rate [LV strain longitudinal (LVSL), LV strain radial (LVSR), LV strain circumferential (LVSC), LV strain rate longitudinal (LVSRL), LV strain rate radial (LVSRR), and LV strain rate circumferential (LVSRC)], along with late gadolinium enhancement (LGE), perfusion deficit, and CALs in related segments were analyzed. The KD group was subdivided by CALs, perfusion, and LGE results, and strain results were compared with controls and in subgroups.

Results: Cardiac fibrosis and ischemia were not confined to the territory of CALs. In a global analysis, strain and strain rates were lower in the KD group, especially in the subgroup with LGE and perfusion deficit. In segmental analysis, LVSR, LVSC, LVSL, and LVSRR decreased in the giant aneurysm group, and a lower LVSR $(20.369 \% \pm 10.603 \%$ vs. $26.071 \% \pm 12.349 \%)$ and LVSC $(-13.37 \% \pm 5.365 \%$ vs. $-15.847 \% \pm 5.778 \%)$ were observed in thrombosed segments. The strain and strain rate were all lower in segments with LGE and perfusion deficit, and no obvious difference was found between groups with and without stenosis. LVSR had a better ability to identify giant aneurysm, thrombosis, stenosis, perfusion deficit, and LGE.

Conclusions: We detected lower strain values in KD patients, which was more pronounced in segments with aneurysm, thrombi, LGE, and perfusion deficit. LVSR is useful to discern patients with higher risk.

Keywords: Cardiac magnetic resonance (CMR); feature tracking; Kawasaki disease (KD); myocardial fibrosis; coronary artery aneurysm (CAA); thrombosis

Submitted Dec 29, 2020. Accepted for publication Jun 07, 2021.

doi: $10.21037 /$ qims-20-1402

View this article at: https://dx.doi.org/10.21037/qims-20-1402 


\section{Introduction}

Kawasaki disease (KD) is an acute, median size vasculitis, which has been observed worldwide and is more prevalent in Asians. The incidence varies from 39 to 250 in 100,000 children $<5$-year-old and appears to be increasing (1). KD mainly affects the cardiovascular system and can induce morbidity and mortality during the acute and chronic stages. Coronary artery lesions (CALs), especially coronary artery aneurysm (CAA), are the main complications and are related to thrombosis, stenosis, and subsequent myocardial ischemia and fibrosis. The incidence of CAA has decreased from $20 \%$ to less than $5 \%$ due to the use of intravenous immunoglobulin (IVIG) (2).

Apart from CAL, KD usually leads to non-coronary cardiac abnormalities (NCA) affecting the myocardium, pericardium, and endocardium, including valves, all of which may be inflamed. During an acute KD episode, myocardial inflammation and edema can be documented in $50-70 \%$ of patients $(3,4)$, and biopsy studies suggest the myocarditis is distributed unevenly, ranging from the regional segments to the entire heart, and develops even earlier than coronary arteritis $(4,5)$. In one Chinese study of $142 \mathrm{KD}$ patients, 106 children $(74.65 \%)$ suffered from NCA, and 23 (16.20\%) developed acute myocarditis (6).

Myocardial ischemia and fibrosis have been seen using cardiac magnetic resonance (CMR) in the subacute and chronic stages of $\mathrm{KD}$, while myocardial mechanical deformation has also been identified, even in patients with normal cardiac function. However, there is limited data regarding the association of strain abnormality with myocardial ischemia and fibrosis in the chronic phase of $\mathrm{KD}$, and changes to myocardial mechanics caused by CALs are unclear. We aimed to quantify left ventricular (LV) contractility associations with myocardial ischemia, fibrosis, and CALs.

\section{Methods}

\section{Patients and controls}

The study was performed in The Children's Hospital of Fudan University, Shanghai, and KD patients were given CMR examination between May 2013 and April 2020. Disease stages were defined as follows: acute, as days 1-14, subacute, as days $15-42$, and convalescence/chronic as after day 43 (7), with day 1 defined as the first day of clinical signs, including fever, rash, and lymphadenopathy. A control group composed of 20 age- and sex-matched healthy volunteers was also formed. The study was conducted in accordance with the Declaration of Helsinki (as revised in 2013) and was approved by the Ethics Committee of Children's Hospital of Fudan University. Written informed consent was obtained from the parents of patients and healthy volunteers.

\section{CMR scanning sequence and parameters}

We used a 1.5-T MR (Siemens Medical Solutions, Erlangen, Germany) to produce electrocardiographygated two-dimensional steady-state free precession images in axial and longitude plans for functional assessment and strain analysis. Twenty-five phases per cardiac cycle were acquired with breath-navigation, and the parameters were repetition time (TR) $84 \mathrm{~ms}$, echo time (TE) $3.15 \mathrm{~ms}$, flip angle $62^{\circ}$, voxel size $1.2 \times 1.2 \times 6 \mathrm{~mm}^{3}$, and field-of-view (FOV) $240 \times 240 \mathrm{~mm}^{2}$. To assess fibrosis, late gadolinium enhancement (LGE) images were acquired using a phasesensitive inversion recovery gradient echo sequence, which was performed $10 \mathrm{~min}$ after the administration of gadopentetate dimenglumine (Magnevist, Bayer Healthcare Pharmaceuticals, Berlin, Germany), and the sequence parameters included TR $84 \mathrm{~ms}$, TE $3.15 \mathrm{~ms}$, flip angle $25^{\circ}$, voxel size $2.0 \times 1.5 \times 8 \mathrm{~mm}^{3}$, and FOV $240 \times 240 \mathrm{~mm}^{2}$. An electrocardiography-gated three-dimensional steadystate free precession images sequence with fat saturation prepulses in a whole-heart approach was adopted for CALs evaluation, and the sequence parameters were TR 294-337 $\mathrm{ms}$, TE $3.17 \mathrm{~ms}$, flip angle $90^{\circ}, 1 \mathrm{~mm}$ slice thickness, and FOV $380 \times 420 \mathrm{~mm}^{2}$. First-pass rest and stress perfusion images were conducted for myocardial ischemia. The whole examination time was about $30 \mathrm{~min}$.

\section{CMR image analysis}

CMR images were analyzed by a radiologist who was blinded to the patients' clinical information, and all images were analyzed by the CVI4.2 software package (Circle Cardiovascular Imaging 4.2, Calgary, Canada). 3D steadystate-free-precession (SSFP) images were evaluated for the CALs (CAA, stenosis, and thrombi) and according to the 2017 AHA proposal based on z-score, small $(2.5 \leq Z$-score $<5)$, medium $(5 \leq Z$-score $<10)$, and giant $(Z$-score $\geq 10$ or diameter $\geq 8 \mathrm{~mm}$ ), CAA sizes were classified (2). For shortaxis views, the myocardium of the $\mathrm{LV}$ was divided into 16 segments, with six segments at the mid and basal locations and four at the apical location (8). The strain, perfusion, 

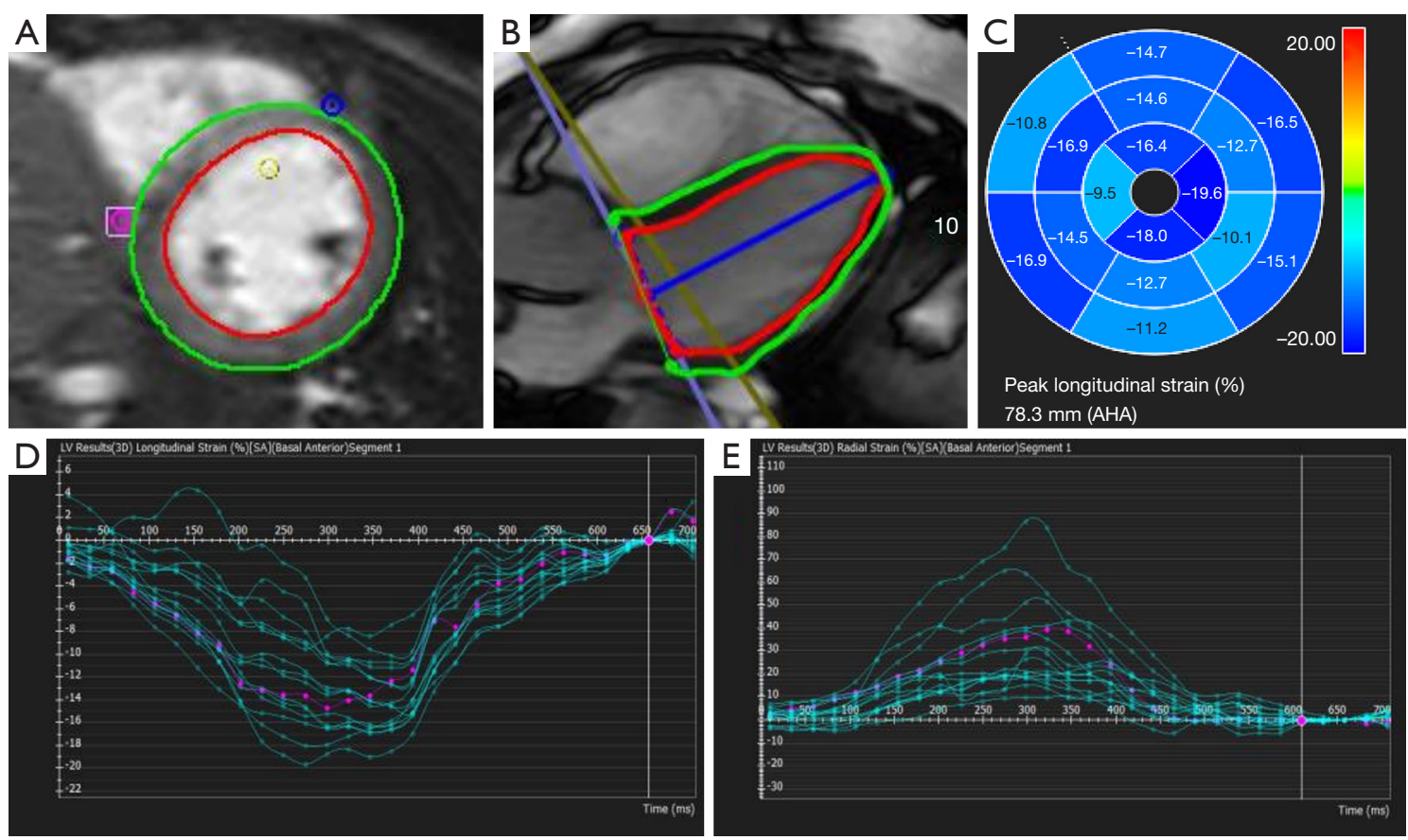

Figure 1 CMR-FT postprocessing LV by CVI42 software. Delineation of endocardial and epicardial borders of LV in end-systolic and enddiastolic phases in the axial short (A) and longitude (B) cine images for strain and strain rate calculation. Longitudinal strain values of 16 segments of LV were demonstrated in a bull's eye diagram (C). Longitudinal strain (E) and radial strain (C) curve of 16 segments of LV in one cardiac cycle were produced. CMR-FT, cardiac magnetic resonance feature tracking; LV, left ventricular.

and LGE images were analyzed in every segment. In LGE analysis, a five-standard deviation threshold above the mean myocardial signal was set, and for strain analysis, a CMR feature tracking (CMR-FT) technique was used. The systolic strain and strain rate were calculated with the delineation of endocardial and epicardial borders in endsystolic and end-diastolic phases (Figure 1). All the three directional (longitudinal, circumferential, and radial) strain and strain rates were measured. The included indices were peak systolic LV strain radial (LVSR), LV strain circumferential (LVSC), LV strain longitudinal (LVSL), LV strain rate radial (LVSRR), LV strain rate circumferential (LVSRC), and LV strain rate longitudinal (LVSRL). For ease of reporting, we referred to positive $(+)$ and negative $(-)$ to represent the existence or non-existence of LGE and perfusion abnormality. Biventricular dimensions were normalized to the body surface area.

Strain measurements of 20 randomly selected patients were repeated by the same investigator and performed by another radiologist to assess intra-observer and inter- observer agreement.

\section{Statistical analysis}

Statistical analysis was carried out using SPSS 26 software (IBM, NY, USA). Continuous variables were expressed as mean \pm standard deviation, and categorical variables were expressed as the number and percent. For continuous variables, the comparison of subgroups was conducted using unpaired student $t$-test and one-way analysis of variance (ANOVA) with Bonferroni correction. Diagnostic accuracy of CMR-FT results was evaluated by applying receiver operating characteristic (ROC) curve analysis, and for the area under the curve (AUC), 0.9-1.0 was considered excellent, $0.75-0.9$ stood for good, 0.6-0.75 marked moderate, and 0.5-0.6 was poor. Best cut-off value, sensitivity, and specificity were derived from ROC curves, and intra- and inter-observer variability was assessed using Cronbach's $\alpha$ (9), and $\mathrm{P}<0.05$ was considered statistically significant. 
Table 1 Clinical features of KD patients and controls

\begin{tabular}{|c|c|}
\hline Features & Value \\
\hline \multicolumn{2}{|l|}{ Sex } \\
\hline Male & 64 \\
\hline Female & 12 \\
\hline Age of onset (month, IQR) & $32.113 \pm 33.242[8-45]$ \\
\hline Interval of exam (month, IQR) & $29.900 \pm 38.264[2-48]$ \\
\hline \multicolumn{2}{|l|}{ CMR } \\
\hline LVEF (\%) & $61.950 \pm 6.794$ \\
\hline LVEDVi $\left(\mathrm{mL} / \mathrm{m}^{2}\right)$ & $70.448 \pm 16.440$ \\
\hline LVESVi $\left(\mathrm{mL} / \mathrm{m}^{2}\right)$ & $27.491 \pm 11.692$ \\
\hline RVEF (\%) & $56.136 \pm 6.610$ \\
\hline RVEDVi $\left(\mathrm{mL} / \mathrm{m}^{2}\right)$ & $71.799 \pm 13.765$ \\
\hline RVESVi $\left(\mathrm{mL} / \mathrm{m}^{2}\right)$ & $31.788 \pm 8.904$ \\
\hline Cardiac index $\left(\mathrm{L} / \mathrm{min} / \mathrm{m}^{2}\right)$ & $2.744 \pm 0.420$ \\
\hline Heart rate (beat/min) & $80-115$ \\
\hline \multicolumn{2}{|l|}{ Segments with CAAs } \\
\hline Small & $60 / 1,216(4.934 \%)$ \\
\hline Median & $72 / 1,216(5.921 \%)$ \\
\hline Giant & $257 / 1,216(21.135 \%)$ \\
\hline Segments with thrombosis & $81 / 1,216(6.661 \%)$ \\
\hline Segments with stenosis & $14 / 1,216(1.151 \%)$ \\
\hline Segments with LGE & $91 / 1,216(7.484 \%)$ \\
\hline Segments with perfusion deficit & $114 / 1,216(9.375 \%)$ \\
\hline
\end{tabular}

$\mathrm{KD}$, Kawasaki disease; IQR, inter-quartile range; CMR, cardiac magnetic resonance; LVEF, left ventricular ejection fraction; LVEDVi, left ventricular end-diastolic volume index; LVESVi, left ventricular end-systolic volume index; RVEF, right ventricular ejection fraction; RVEDVi, right ventricular end-diastolic volume index; RVESVi, right ventricular end-systolic volume index; CAA, coronary artery aneurysm; LGE, late gadolinium enhancement.

\section{Results}

\section{Clinical features}

Table 1 shows the clinical characteristics of all $\mathrm{KD}$ patients and controls. Of the 102 cases with CMR found between May 2013 and April 2020, 10 were without LGE or perfusion sequence, nine were without cine sequence for CMR-FT evaluation, and the quality of the images in seven cases was insufficient for CAL evaluation, leaving 76 cases for further analysis. The average age of onset was $32.113 \pm 33.242$ months old [inter-quartile range (IQR), 8-45 months], and the median interval to CMR examination was $29.900 \pm 38.264$ months (IQR, 2-48 months). All patients were in the convalescent/ chronic phase, and all received optimal treatment, including IVIG, during the acute phase. Seven patients (9.090\%) had impaired LV ejection fraction (LVEF) during the acute phase. During convalescence, all patients were asymptomatic, and the $\mathrm{LV}$ cardiac function of all was normal.

The 20 healthy volunteers in the control group had normal CMR without evidence of cardiac disease.

\section{Global strain indices comparison in KD vs. controls groups and in KD subgroups}

Global LV strain indices in $\mathrm{KD}$ and control groups are shown in Table 2.

Compared with controls, KD patients had lower strain and strain rates except for LVSL $(-13.975 \% \pm 4.366 \%$ vs. $-16.568 \% \pm 4.790 \%, \mathrm{P}<0.05)$, although the differences did not reach statistical significance.

In KD patients with LGE in LV, all strain indices were lower than the LGE (-) subgroup, with statistical significance. In KD patients with a $\mathrm{LV}$ perfusion deficit, lower LVSR $(21.955 \% \pm 10.801 \%$ vs. $25.173 \% \pm 5.150 \%$, $\mathrm{P}<0.05)$, LVSC $(-13.961 \% \pm 5.639 \%$ vs. $-16.082 \% \pm 2.418 \%$, $\mathrm{P}<0.05)$, LVSL $(-12.546 \% \pm 4.713 \%$ vs. $-14.676 \% \pm 4.050 \%$, $\mathrm{P}<0.05)$, and LVSRL $(-1.008 \pm 0.378 / \mathrm{s}$ vs. $-1.213 \pm 0.482 / \mathrm{s}$, $\mathrm{P}<0.05)$ were observed, reaching statistical significance. There were also lower LVSRC and LVSRR, but this did not reach statistical significance.

\section{CMR segmental analysis}

Each CMR had 16 segments, with 1,216 (16×76) segments in total. The coronary artery in the territory of every segment was analyzed according to the size of CAA, thrombosed and non-thrombosed, stenosis $(+)$ or stenosis $(-)$, LGE $(+)$ and LGE (-), and perfusion deficit (+) and perfusion deficit (-), and all the segments were divided into subgroups. Among the 1,216 segments, the number of segments with small, medium, and giant CAA was 60, 72, and 257, respectively. In the 1,216 segments, 14 segments had stenosis, 81 with thrombi, 114 with perfusion deficit, and 91 with LGE.

Figure 2 shows that among the 114 segments with perfusion deficit, the number of segments with giant CAA, thrombosis, and stenosis was 37 (32.456\%), 26 $(22.807 \%)$, and $1(0.977 \%)$, respectively, and among all the 91 segments with LGE, the number of giant CAA, 
Table 2 Comparison of global LV strain and strain rate between healthy volunteers, KD patients, and subgroups

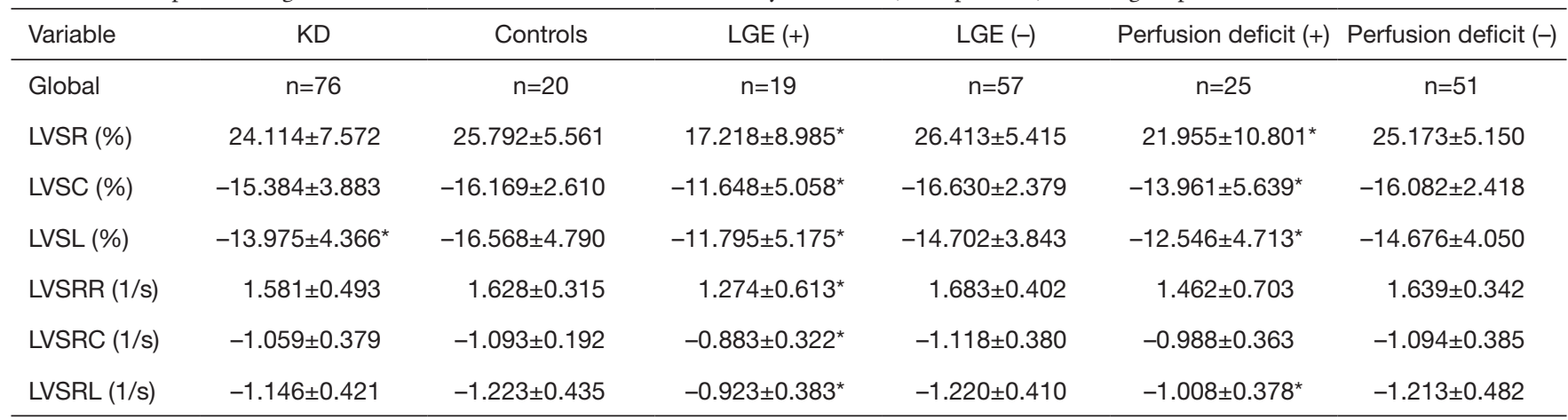

* presenting data with $\mathrm{P}<0.05$ compared between KD and controls; LGE (+) and LGE (-); perfusion deficit (+) and perfusion deficit (-). LV, left ventricular; KD, Kawasaki disease; LVSR, left ventricular strain radial; LVSC, left ventricular strain circumferential; LVSL, left ventricular strain longitudinal; LVSRR, left ventricular strain rate radial; LVSRC, left ventricular strain rate circumferential; LVSRL, left ventricular strain rate longitudinal; LGE, late gadolinium enhancement.

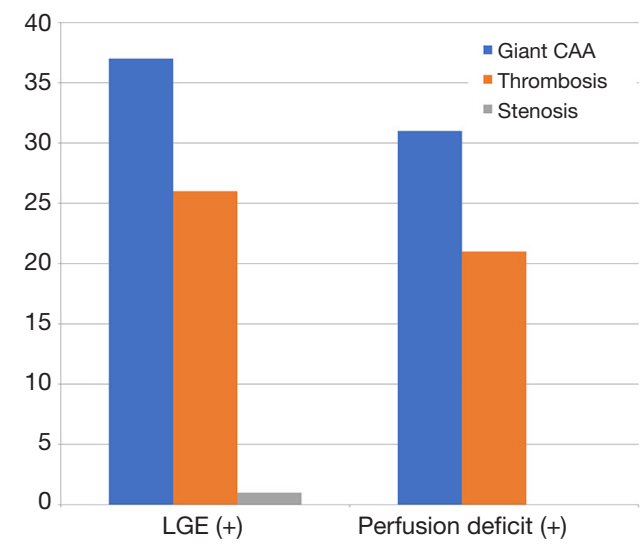

Figure 2 Number of segments with coronary lesions in LGE (+) and perfusion deficit group. In the 91 segments with LGE, the number of giant CAA, thrombi, and stenosis was 31, 21, and 0 , respectively. In the 114 segments with perfusion deficit, the number of giant CAA, thrombosis and stenosis was 37, 26, and 1, respectively. LGE, late gadolinium enhancement; CAA, coronary artery aneurysm.

thrombosis, and stenosis was 31 (34.066\%), 21 (23.077\%), and 0 , respectively. All segments with LGE (+) were in the regions of perfusion deficit, and $63(77.778 \%)$ segments with thrombosis had giant CAA.

\section{Strain indices in KD segmental analysis}

These results are shown in Table 3.

When comparing segments with different sizes of CAAs, LVSR, LVSC, LVSL, and LVSRR decreased with
CAA level, indicating significant differences. Patients with larger CAA also had lower LVSRC and LVSRL, while no statistically significant difference was displayed.

Similarly, lower LVSR $(20.369 \% \pm 10.603 \%$ vs. $26.071 \% \pm 12.349 \%, \mathrm{P}<0.05)$ and LVSC $(-13.37 \% \pm 5.365 \%$ vs. $-15.847 \% \pm 5.778 \%, \mathrm{P}<0.05)$ were observed in thrombosed segments with statistical significance. No obvious difference was found between groups with and without stenosis, and all the strain indices were lower in the segments with LGE and perfusion deficit, suggesting statistical significance.

\section{ROC analysis}

The ROC curve revealed that LVSR had a better ability to identify $\mathrm{KD}$ with giant $\mathrm{CAA}$, thrombosis, stenosis, perfusion deficit, and LGE, with the highest AUC in all indices (Table 4, Figure 3).

\section{Intra-observer and inter-observer agreement}

We evaluated the intra-observer and inter-observer agreement by Cronbach's $\alpha$. If the value is higher than 0.8 , the reliability is high; between 0.7 and 0.8 , the reliability is good; between 0.6 and 0.7 is considered acceptable; and less than 0.6 , the reliability is poor. In the CMR-based strain parameters, there was no poor reliability in intra-observer and inter-observer agreement.

\section{Discussion}

Both coronary macro-and microvascular function should 

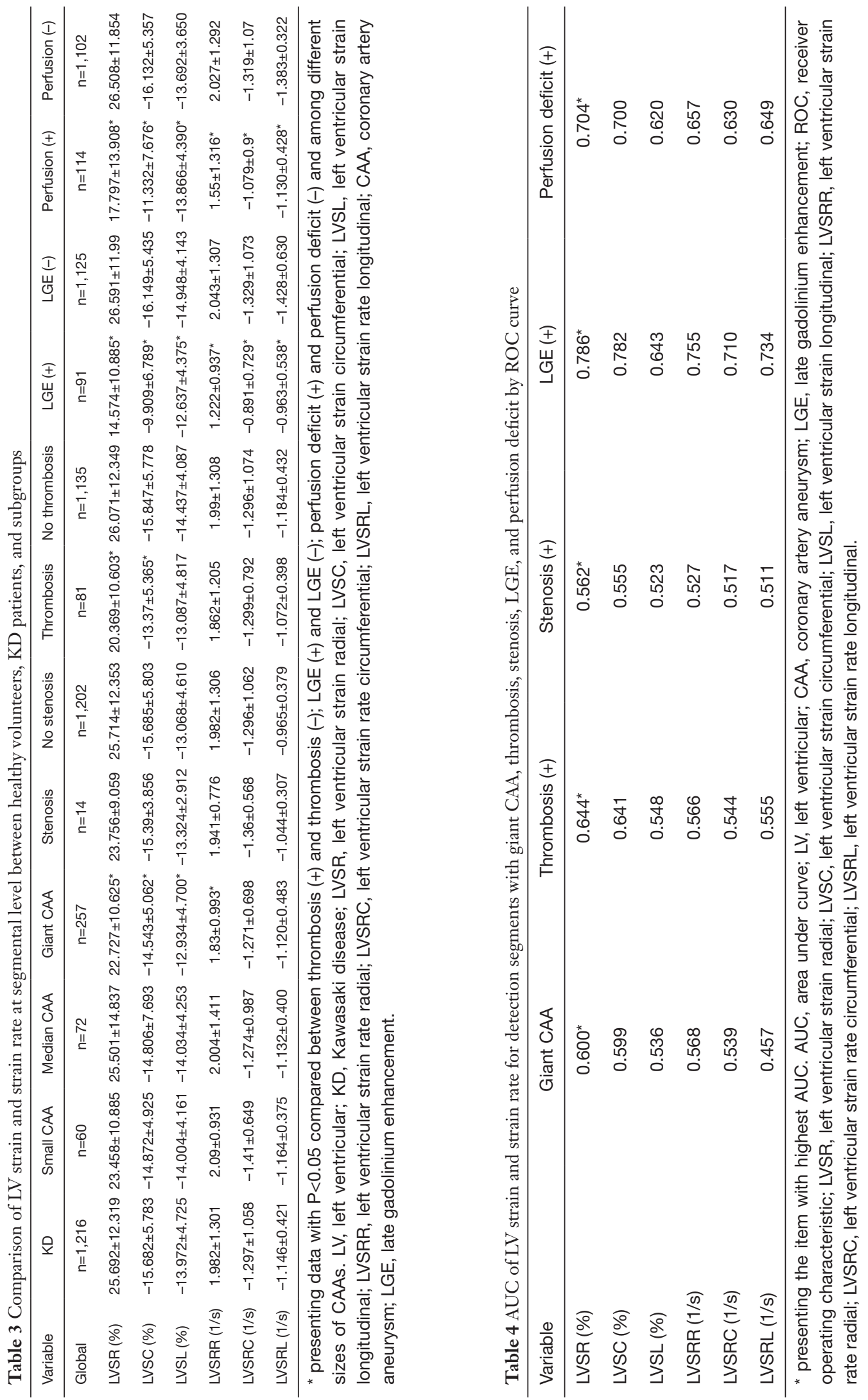

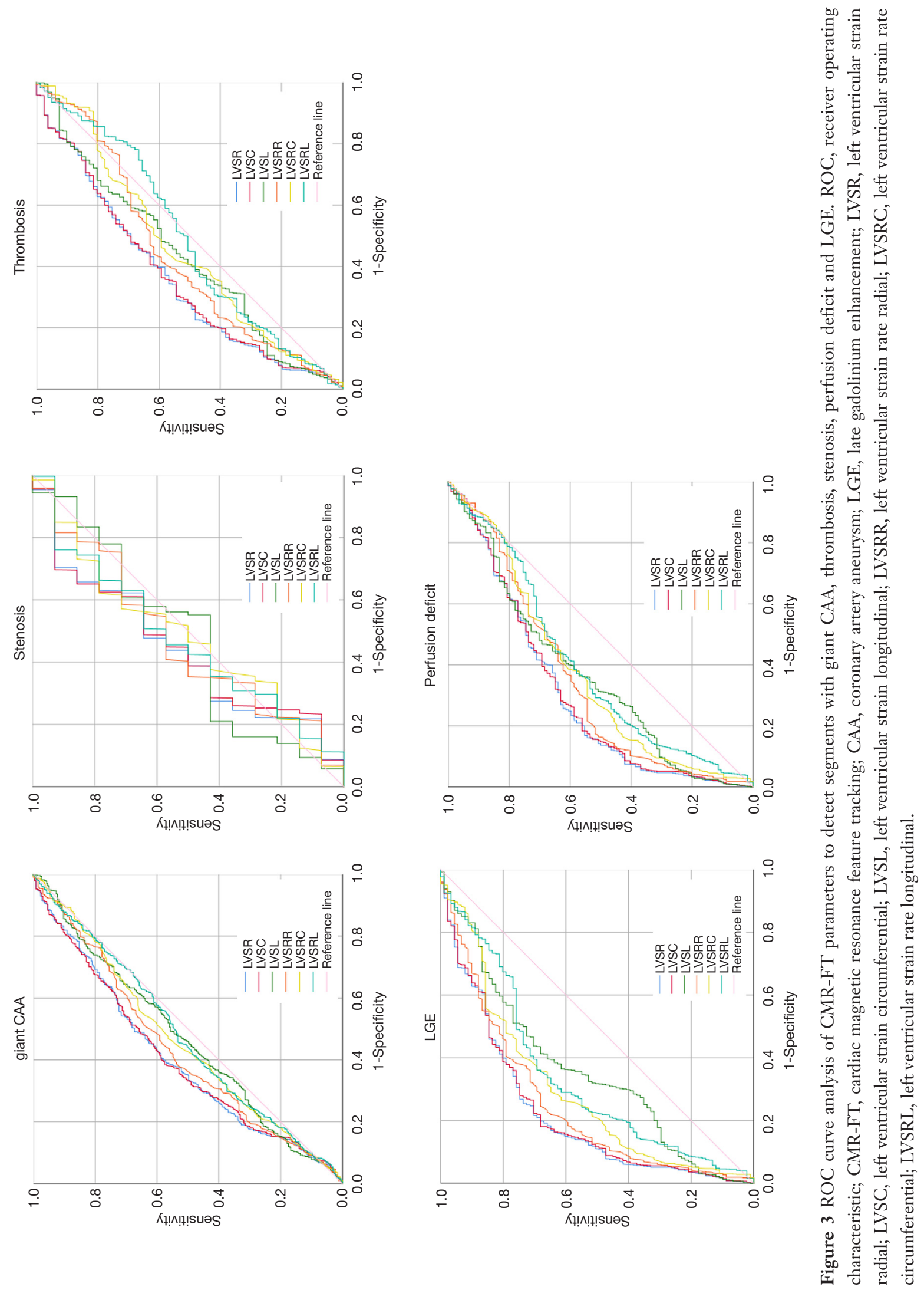
be evaluated in patients with KD (10). KD subjects with giant aneurysms had significantly higher biomarkers of inflammation and fibrosis, indicating a more severe inflammatory process $(11,12)$, and with giant CAA, the incidence of thrombosis and stenosis was higher and related to myocardial ischemia (13). Doan found that the incidence of hypoperfusion during stress perfusion CMR was $39 \%$, with an overall agreement with moderate-tosevere CAA (14). The chronic cardiovascular impact of $\mathrm{KD}$ may manifest not only in coronary artery geometry but also in the structure and function of the arterial endothelium and wall (5). Some studies revealed that the myocardial blood flow reversed, reduced, and impaired vasoconstriction and vasodilatation contributed to the diffuse ischemia and fibrosis that extended the territories supplied by giant aneurysms $(13,15)$. Myocarditis in KD is characterized by inflammatory infiltration without obvious myocardial necrosis, and the incidence of LGE is not high (14); and in our research, all the segments with LGE were accompanied by perfusion deficit. However, the segments with LGE and perfusion deficit were not confined in the territory of CALs, suggesting an impairment of the myocardial microcirculation, independent of the status of CALs.

In $\mathrm{KD}$, decreased ventricular contractility may be caused by the combination of myocardial inflammation, microvascular injury, and complications of CALs (16). For patients with CAAs, the myocardial deformation was more obvious (17) and could be improved after treatment and in regressed CAAs (7). Our research showed impaired contractility in segments supplied by severe CAA, and this was associated with thrombosis. KD with CAA may have macro-and microvascular dysfunction, which may explain why some strain parameters decreased in the KD with CAA. Stenosis did not show any relation with contractility abnormality, indicating that it did not affect coronary vascular flow. However, in a study of ischemic heart disease caused by stress CMR, decreased strain values were identified in stenotic segments (18). Increased fibrosis and decreased perfusion are associated with reduced contractility (16), and a linear correlation between the amount of LGE and the degree of strain impairment has been discovered in pulmonary hypertension (19), hypertrophic cardiomyopathy (20), and acute myocarditis (21). For patients with arrhythmogenic right ventricular cardiomyopathy after radiation ablation (22), idiopathic inflammatory myopathy (23), and isolated LV noncompaction (24), the strain was lower in segments with scar and LGE. LGE is also an independent predictor of combined endpoint, including multiple cardiac events (25). We observed LGE that was caused by myocardial fibrosis in six patients, and segments with LGE and perfusion deficit showed obviously reduced contractility, indicating that fibrotic remodeling and microvascular dysfunction translated into a loss of myocardial function. Therefore, early LV dysfunction should be carefully considered in KD patients, particularly if LGE and perfusion deficit are present.

In many clinical scenarios, strain analysis is superior to conventional cardiac function in evaluating subclinical LV systolic dysfunction such as KD and can be applied clinically, especially when the ejection fraction is still preserved. In our research, even in KD patients with normal ejection fraction, strain assessment showed a decrease in at least one component of systolic strains. We also found that LV dysfunction persisted beyond the acute phase. However, all studies demonstrated a wide range of strain values, and some results even conflicted with others. The LV myocardial architecture is organized by three layers of different orientations, and the different impaired strains in different diseases suggest different pathologic mechanisms (26). LV global longitudinal strain has shown prognostic value for the prediction of cardiac events, including KD $(27,28)$. Yu et al. (29) and Frank et al. (30) showed that depressed longitudinal strain is associated with inflammatory biomarkers. Some studies have also revealed the circumferential strain displaying mid-wall fibrosis in ischemic heart disease (18), dilated cardiomyopathy (31), as well as KD (30,32). Bratis et al. (7) and Lin et al. (33) discovered reduced longitudinal and circumferential strain related to CALs. In the acute phase of KD, LVSR decreased in the basal and middle levels (29). It was also found that LVSR decreased in KD patients with CALs (32). Some research has also shown the value of LVSR in another disease. In repaired tetralogy of Fallot, the decrease of LVSR was related to the risk of death (34). In tricuspid atresia with Fontan surgery (35), acute myocarditis (21), systemic sclerosis (36), COA repaired patients (37), hypertrophic and dilated cardiomyopathy $(38,39)$, significantly reduced LVSR was found compared with controls, indicating good diagnostic performance. In our research, it was clear that LVSL reduced most in the KD group. LVSR, LVSC, and LVSL were lower in segments supplied by severely CAA, and LVSR and LVSC were associated with thrombosis. The ROC showed LVSR had the highest sensitivity and specificity for myocardial lesions. We also discovered that the value of strain was lower for children than adults $(26,40)$, which may be caused by the less thick myocardial layers of 
LV that have weaker wall motion in children. Some papers have shown the value of strain rate to reflect myocardial function (28) while others showed no difference $(29,30)$. However, due to limited knowledge of normal strain values and the limited sample size, more research is required.

$\mathrm{KD}$ may give rise to a complicated set of cardiovascular problems later in life, and the need for long-term surveillance of both CALs and non-coronary lesions is high. Both echocardiographic speckle-tracking and CMR-FT currently provide measurements of strain values applied in different clinical scenarios. Recently, CMR-FT has become a subject of great interest, providing better tissue contrast and regional analysis of myocardial mechanical dysfunction in variable cardiac diseases. As a post-processing method, CMR-FT can be applied to routinely cine CMR sequence and can be conducted without carrying out additional sequences. CMR-FT has good reproducibility and low inter-reader and intra-reader variability, making it a powerful tool to support decision-making and follow-up. The main disadvantages of CMR-FT include the throughplane motion artifacts that are limited by pixel size, lacking standardization in large samples (26).

Although the sample size in this study was large, some limitations are present. (I) As KD children without CALs were not enrolled, the data of this subgroup is not included. (II) There is a lack of long-term follow-up of CMR-FT, especially in the adult period. (III) There is currently no consensus on normal values for myocardial deformation in children (30). Future research should address these issues.

\section{Conclusions}

In contrast to previous reports that focused on global ventricular function, this study investigated the association among CALs, myocardial fibrosis, ischemia, and tissue architecture on a segmental level. We found that cardiac fibrosis and ischemia were not confined in the territory of CALs. We detected lower strain values in KD patients than normal controls, and these were more pronounced in segments with CAAs, thrombi, LGE, and perfusion deficit. Strain analysis may improve our understanding of ventricular mechanics late after $\mathrm{KD}$ and facilitate the early detection of subclinical cardiac dysfunction.

\section{Acknowledgments}

The scientific guarantor of this publication is Dr. Guo-Ying Huang.
Funding: This study has received funding from "The National Key Research and Development Program of China (2016YFC1000500)".

\section{Footnote}

Conflicts of Interest: All authors have completed the ICMJE uniform disclosure form (available at https://dx.doi. org/10.21037/qims-20-1402). The authors have no conflicts of interest to declare.

Ethical Statement: The authors are accountable for all aspects of the work in ensuring that questions related to the accuracy or integrity of any part of the work are appropriately investigated and resolved. The study was conducted in accordance with the Declaration of Helsinki (as revised in 2013). The study was approved by the Ethics Committee of Children's Hospital of Fudan University. Written informed consent was obtained from the parents of patients and healthy volunteers.

Open Access Statement: This is an Open Access article distributed in accordance with the Creative Commons Attribution-NonCommercial-NoDerivs 4.0 International License (CC BY-NC-ND 4.0), which permits the noncommercial replication and distribution of the article with the strict proviso that no changes or edits are made and the original work is properly cited (including links to both the formal publication through the relevant DOI and the license). See: https://creativecommons.org/licenses/by-nc-nd/4.0/.

\section{References}

1. Uehara R, Belay ED. Epidemiology of Kawasaki disease in Asia, Europe, and the United States. J Epidemiol 2012;22:79-85.

2. McCrindle BW, Rowley AH, Newburger JW, Burns JC, Bolger AF, Gewitz M, Baker AL, Jackson MA, Takahashi M, Shah PB, Kobayashi T, Wu MH, Saji TT, Pahl E; American Heart Association Rheumatic Fever, Endocarditis, and Kawasaki Disease Committee of the Council on Cardiovascular Disease in the Young; Council on Cardiovascular and Stroke Nursing; Council on Cardiovascular Surgery and Anesthesia; and Council on Epidemiology and Prevention. Diagnosis, treatment, and long-term management of Kawasaki disease: a scientific statement for health professionals from the American Heart Association. Circulation 2017;135:e927-99. 
3. Kao CH, Hsieh KS, Wang YL, Wang SJ, Yeh SH. The detection of ventricular dysfunction and carditis in children with Kawasaki disease using equilibrium multigated blood pooling ventriculography and $99 \mathrm{Tcm}-$ HMPAO-labelled WBC heart scans. Nucl Med Commun 1993;14:539-43.

4. Harada M, Yokouchi Y, Oharaseki T, Matsui K, Tobayama H, Tanaka N, Akimoto K, Takahashi K, Kishiro M, Shimizu T, Takahashi K. Histopathological characteristics of myocarditis in acute-phase Kawasaki disease. Histopathology 2012;61:1156-67.

5. Orenstein JM, Shulman ST, Fox LM, Baker SC, Takahashi M, Bhatti TR, Russo PA, Mierau GW, de Chadarévian JP, Perlman EJ, Trevenen C, Rotta AT, Kalelkar MB, Rowley AH. Three linked vasculopathic processes characterize Kawasaki disease: a light and transmission electron microscopic study. PLoS One 2012;7:e38998.

6. Liu FF, Liu HH, Qiu Z, Wang JJ, Samadli S, Wu Y, Wu YF, Xu Y, Luo HH, Chen WX, Zhang DD, Hu P. Clinical observation of noncoronary cardiac abnormalities in Chinese children with Kawasaki disease. Eur J Clin Invest 2020;50:e13210.

7. Bratis K, Hachmann P, Child N, Krasemann T, Hussain T, Mavrogeni S, Botnar R, Razavi R, Greil G. Cardiac magnetic resonance feature tracking in Kawasaki disease convalescence. Ann Pediatr Cardiol 2017;10:18-25.

8. Balasubramanian S, Harrild DM, Kerur B, Marcus E, Del Nido P, Geva T, Powell AJ. Impact of surgical pulmonary valve replacement on ventricular strain and synchrony in patients with repaired tetralogy of Fallot: a cardiovascular magnetic resonance feature tracking study. J Cardiovasc Magn Reson 2018;20:37.

9. Eisinga R, Grotenhuis Mt, Pelzer B. The reliability of a two-item scale: Pearson, Cronbach, or Spearman-Brown? Int J Public Health 2013;58:637-42.

10. Feher A, Sinusas AJ. Quantitative assessment of coronary microvascular function: dynamic single-photon emission computed tomography, positron emission tomography, ultrasound, computed tomography, and magnetic resonance imaging. Circ Cardiovasc Imaging 2017;10:e006427.

11. Printz BF, Sleeper LA, Newburger JW, Minich LL, Bradley T, Cohen MS, Frank D, Li JS, Margossian R, Shirali G, Takahashi M, Colan SD, Pediatric Heart Network Investigators. Noncoronary cardiac abnormalities are associated with coronary artery dilation and with laboratory inflammatory markers in acute Kawasaki disease. J Am Coll Cardiol 2011;57:86-92.
12. Hoshino S, Shimizu C, Jain S, He F, Tremoulet AH, Burns JC. Biomarkers of inflammation and fibrosis in Kawasaki disease patients years after initial presentation with low ejection fraction. J Am Heart Assoc 2020;9:e014569.

13. Friesen RM, Schäfer M, Jone PN, Appiawiah N, Vargas D, Fonseca B, DiMaria MV, Truong U, Malone L, Browne LP. Myocardial perfusion reserve index in children with Kawasaki disease. J Magn Reson Imaging 2018;48:132-9.

14. Doan TT, Wilkinson JC, Loar RW, Pednekar AS, Masand PM, Noel CV. Regadenoson stress perfusion cardiac magnetic resonance imaging in children with Kawasaki disease and coronary artery disease. Am J Cardiol 2019;124:1125-32.

15. Iemura $M$, Ishii $M$, Sugimura T, Akagi T, Kato H. Long term consequences of regressed coronary aneurysms after Kawasaki disease: vascular wall morphology and function. Heart 2000;83:307-11.

16. Muthusami P, Luining W, McCrindle B, van der Geest R, Riesenkampff E, Yoo SJ, Seed M, Manlhiot C, GrosseWortmann L. Myocardial perfusion, fibrosis, and contractility in children with Kawasaki disease. JACC Cardiovasc Imaging 2018;11:1922-4.

17. Sanchez AA, Sexson Tejtel SK, Almeida-Jones ME, Feagin DK Jr, Altman CA, Pignatelli RH. Comprehensive left ventricular myocardial deformation assessment in children with Kawasaki disease. Congenit Heart Dis 2019;14:1024-31.

18. Schneeweis C, Qiu J, Schnackenburg B, Berger A, Kelle S, Fleck E, Gebker R. Value of additional strain analysis with feature tracking in dobutamine stress cardiovascular magnetic resonance for detecting coronary artery disease. J Cardiovasc Magn Reson 2014;16:72.

19. de Siqueira ME, Pozo E, Fernandes VR, Sengupta PP, Modesto K, Gupta SS, Barbeito-Caamaño C, Narula J, Fuster V, Caixeta A, Sanz J. Characterization and clinical significance of right ventricular mechanics in pulmonary hypertension evaluated with cardiovascular magnetic resonance feature tracking. J Cardiovasc Magn Reson 2016;18:39.

20. Nucifora G, Muser D, Gianfagna P, Morocutti G, Proclemer A. Systolic and diastolic myocardial mechanics in hypertrophic cardiomyopathy and their link to the extent of hypertrophy, replacement fibrosis and interstitial fibrosis. Int J Cardiovasc Imaging 2015;31:1603-10.

21. Chen X, Hu H, Pan J, Shu J, Hu Y, Yu R. Performance of cardiovascular magnetic resonance strain in patients 
with acute myocarditis. Cardiovasc Diagn Ther 2020;10:725-37.

22. Zghaib T, Ghasabeh MA, Assis FR, Chrispin J, Keramati A, Misra S, Berger R, Calkins H, Kamel I, Nazarian S, Zimmerman S, Tandri H. Regional strain by cardiac magnetic resonance imaging improves detection of right ventricular scar compared with late gadolinium enhancement on a multimodality scar evaluation in patients with arrhythmogenic right ventricular cardiomyopathy. Circ Cardiovasc Imaging 2018;11:e007546.

23. Kersten J, Güleroglu AM, Rosenbohm A, Buckert D, Ludolph AC, Hackenbroch C, Beer M, Bernhardt P. Myocardial involvement and deformation abnormalities in idiopathic inflammatory myopathy assessed by CMR feature tracking. Int J Cardiovasc Imaging 2021;37:597-603.

24. Zhang J, Jiang M, Zheng C, Liu H, Guo Y, Xie X, Zou Z, Zhou X, Xia L, Luo M, Zeng M. Evaluation of isolated left ventricular noncompaction using cardiac magnetic resonance tissue tracking in global, regional and layerspecific strains. Sci Rep 2021;11:7183.

25. Aquaro GD, Perfetti M, Camastra G, Monti L, Dellegrottaglie S, Moro C, Pepe A, Todiere G, Lanzillo C, Scatteia A, Di Roma M, Pontone G, Perazzolo Marra M, Barison A, Di Bella G; Cardiac Magnetic Resonance Working Group of the Italian Society of Cardiology. Cardiac MR with late gadolinium enhancement in acute myocarditis with preserved systolic function: ITAMY study. J Am Coll Cardiol 2017;70:1977-87.

26. Scatteia A, Baritussio A, Bucciarelli-Ducci C. Strain imaging using cardiac magnetic resonance. Heart Fail Rev 2017;22:465-76.

27. Kang SJ, Jin BK, Hwang SJ, Kim HJ. Sequential changes in left ventricular systolic myocardial deformation mechanics in children with recurrent Kawasaki disease. J Cardiovasc Imaging 2018;26:147-54.

28. McCandless RT, Minich LL, Wilkinson SE, McFadden ML, Tani LY, Menon SC. Myocardial strain and strain rate in Kawasaki disease. Eur Heart J Cardiovasc Imaging 2013;14:1061-8.

29. Yu JJ, Choi HS, Kim YB, Son JS, Kim YH, Ko JK, Park IS. Analyses of left ventricular myocardial deformation by speckle-tracking imaging during the acute phase of Kawasaki disease. Pediatr Cardiol 2010;31:807-12.

30. Frank B, Davidson J, Tong S, Martin B, Heizer H, Anderson MS, Glode MP, Dominguez SR, Jone PN. Myocardial strain and strain rate in Kawasaki disease: range, recovery, and relationship to systemic inflammation/coronary artery dilation. J Clin Exp Cardiolog 2016;7:432.

31. Taylor RJ, Umar F, Lin EL, Ahmed A, Moody WE, Mazur W, Stegemann B, Townend JN, Steeds RP, Leyva F. Mechanical effects of left ventricular midwall fibrosis in non-ischemic cardiomyopathy. J Cardiovasc Magn Reson 2016;18:1.

32. Eun LY, Kim JH, Jung JW, Choi JY. Myocardial layers specific strain analysis for the acute phase of infant Kawasaki disease. Pediatr Cardiol 2016;37:1404-8.

33. Lin Z, Zheng J, Chen W, Ding T, Yu W, Xia B. Assessing left ventricular systolic function in children with a history of Kawasaki disease. BMC Cardiovasc Disord 2020;20:131.

34. Orwat S, Diller GP, Kempny A, Radke R, Peters B, Kühne T, Boethig D, Gutberlet M, Dubowy KO, Beerbaum P, Sarikouch S, Baumgartner H, German Competence Network for Congenital Heart Defects Investigators. Myocardial deformation parameters predict outcome in patients with repaired tetralogy of Fallot. Heart 2016;102:209-15.

35. Ho PK, Lai CT, Wong SJ, Cheung YF. Threedimensional mechanical dyssynchrony and myocardial deformation of the left ventricle in patients with tricuspid atresia after Fontan procedure. J Am Soc Echocardiogr 2012;25:393-400.

36. Bratis K, Lindholm A, Hesselstrand R, Arheden H, Karabela G, Stavropoulos E, Katsifis G, Kolovou G, Kitas GD, Sfikakis PP, Koutsogeorgopoulou L, Mavrogeni $\mathrm{S}$, Ostenfeld E. CMR feature tracking in cardiac asymptomatic systemic sclerosis: Clinical implications. PLoS One 2019;14:e221021.

37. Kutty S, Rangamani S, Venkataraman J, Li L, Schuster A, Fletcher SE, Danford DA, Beerbaum P. Reduced global longitudinal and radial strain with normal left ventricular ejection fraction late after effective repair of aortic coarctation: a CMR feature tracking study. Int J Cardiovasc Imaging 2013;29:141-50.

38. Bogarapu S, Puchalski MD, Everitt MD, Williams RV, Weng HY, Menon SC. Novel cardiac magnetic resonance feature tracking (CMR-FT) analysis for detection of myocardial fibrosis in pediatric hypertrophic cardiomyopathy. Pediatr Cardiol 2016;37:663-73.

39. Buss SJ, Breuninger K, Lehrke S, Voss A, Galuschky C, Lossnitzer D, Andre F, Ehlermann P, Franke J, Taeger T, Frankenstein L, Steen H, Meder B, Giannitsis E, Katus HA, Korosoglou G. Assessment of myocardial deformation with cardiac magnetic resonance strain imaging improves 
risk stratification in patients with dilated cardiomyopathy. Eur Heart J Cardiovasc Imaging 2015;16:307-15.

40. Taylor RJ, Moody WE, Umar F, Edwards NC, Taylor TJ, Stegemann B, Townend JN, Hor KN, Steeds RP, Mazur

Cite this article as: Yao Q, Hu XH, He LL. Evaluation of comprehensive myocardial contractility in children with Kawasaki disease by cardiac magnetic resonance in a large single center. Quant Imaging Med Surg 2022;12(1):481-492. doi: 10.21037/qims-20-1402
W, Leyva F. Myocardial strain measurement with featuretracking cardiovascular magnetic resonance: normal values. Eur Heart J Cardiovasc Imaging 2015;16:871-81. 